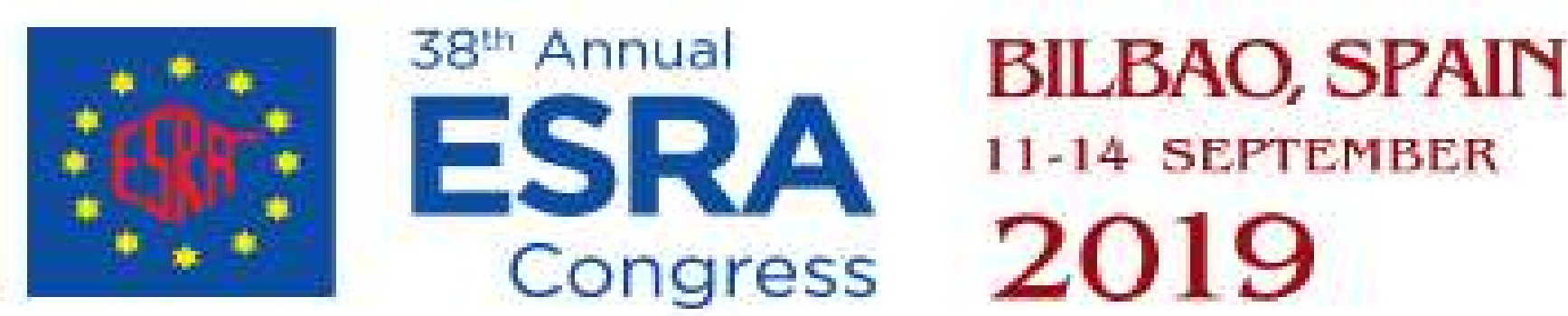

\title{
DISTANCE FROM SKIN TO EPIDURAL SPACE: CORRELATION WITH ANTHROPOMETRIC MEASUREMENTS
}

M.E. Michel Tactuk, R. Sanchis Dux, Y.B. Molero Díez, F.A. Ruíz Simón, R. Martín Martín, M. Gómez Fernández. Hospital Virgen de la Concha, Zamora, Spain. Anaesthesiology Department

\section{Background and Aims:}

The depth where epidural space is found from the skin has been studied in multiple occasions. Nowadays, we know that it depends on the subject and at the level where the puncture is performed. Generally, it varies from 4 to $6 \mathrm{~cm}$ in about $80 \%$ of the population. In overweight and obese patients, the distance may be bigger (even until $8 \mathrm{~cm}$ ), but in thin people can be less than $3 \mathrm{~cm}$.

The aim of this study is to know if anthropometric parameters are related to the distance from the skin to the epidural lumbar space in pregnant women.

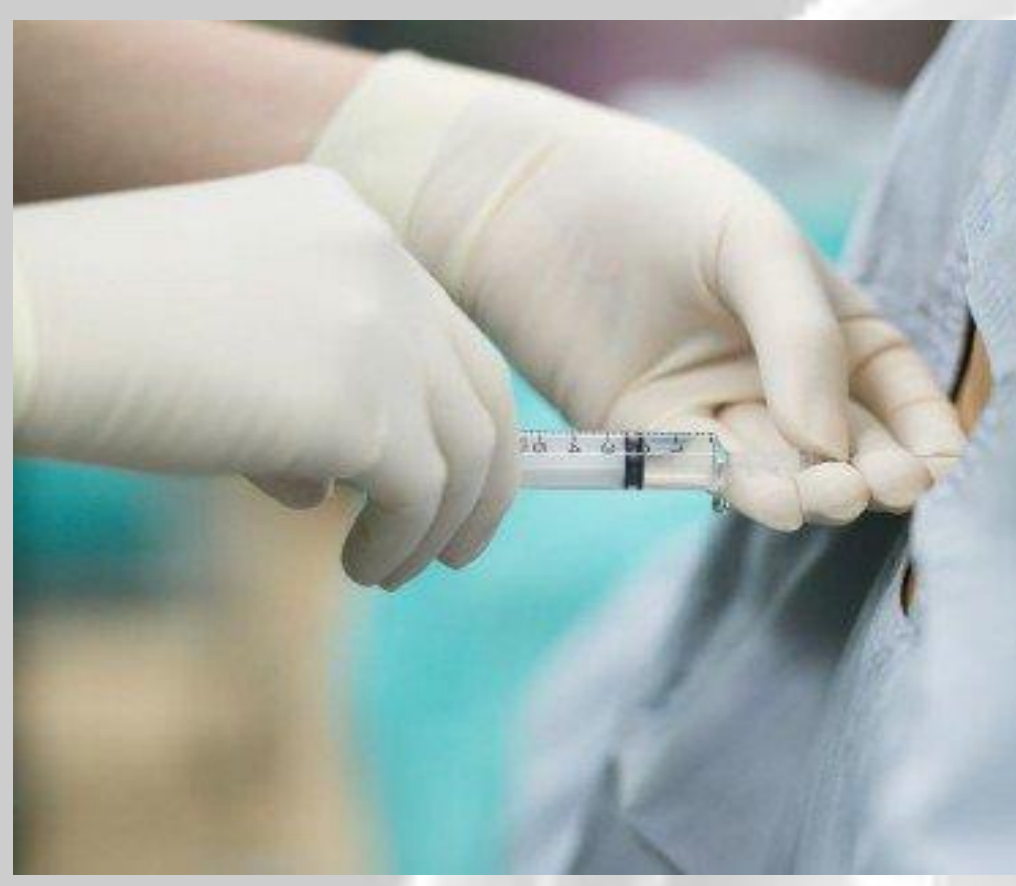

\section{Methods:}

We took 100 obstetric patients who were in labor with continuous epidural analgesia at level L3-L4 with medial approach. Age, weight and height were recorded. The distance to the epidural space was measured from Touhy's needle tip until the first mark where loss of resistance was found.

\section{Results}

The mean distance to epidural space was $5.3 \pm 1 \mathrm{~cm}$. mean height was $162 \pm 7.6 \mathrm{~cm}$. Mean age and weight were $32.1 \pm 5.6$ years and $78.15 \pm 14.6 \mathrm{~kg}$ respectively. The results were statistically significant when we examined the relationship between weight-epidural distance $(p=0.02)$ and BMI-epidural distance $(p=0.043)$.

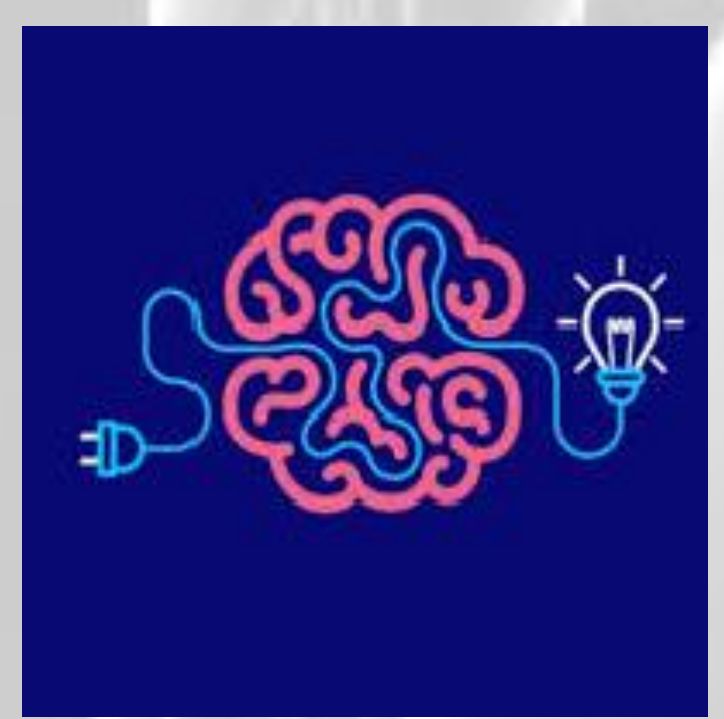

\section{Conclusions:}

$\checkmark$ Elevated BMI and weight are correlated directly with a larger distance from skin to epidural space.

$\checkmark$ Height, only by itself, it is not a determinant factor for a larger distance to the epidural space

$\checkmark$ The distance from skin to epidural space does not depend on patients' age.

\section{BIBLIOGRAPHY}

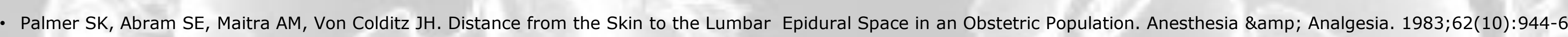

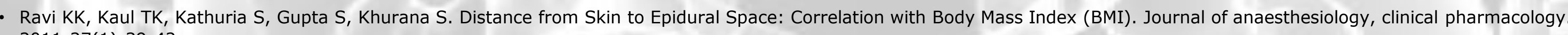
2011;27(1):39-42. 